\title{
Optimized parameters for fluorescence-based verification of ballast water exchange by ships
}

\section{(SUPPORTING INFORMATION)}

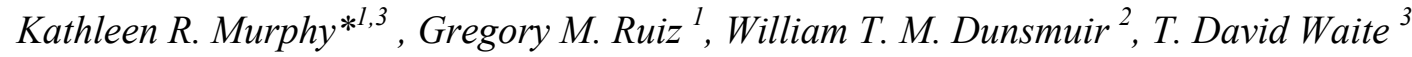 \\ ${ }^{1}$ Smithsonian Environmental Research Center, PO Box 28, Edgewater MD 21037, USA \\ ${ }^{2}$ The University of New South Wales, School of Mathematics, Sydney, NSW 2052, Australia \\ ${ }^{3}$ The University of New South Wales, School of Civil and Environmental Engineering, Sydney, \\ NSW 2052, Australia \\ * Corresponding author: Phone: +61-2-9385-5778, FAX: +61-2-9385-6139, Email: murphyka@si.edu
}

Submitted to Environmental Science and Technology

Revision III - January 20, 2006

Page S1. Table S1 shows the experimental design and sampling schedule for the nine research cruises conducted during this study.

Page S2. Spectral comparisons from fluorometers used in this study are performed. In this section, Figure S1 shows normalized emission scans from fluorometers in this study compared to a published relative technical emission spectrum.

Page S3. Table S2 shows the excitation and emission maxima of the nine fluorescent components identified by the PARAFAC model.

Page S4. Figure S2 shows a validation of the PARAFAC model using rhodamine WT dye.

Page S5. Figure S3 shows a validation of the PARAFAC using split-half analysis.

Page S6. In this section, the methodology for determining optimal wavelengths and thresholds for component isolation and BWE verification is presented. Two figures are included in this section. Figure S4 shows the average isolation of components $\mathrm{C} 2$ and $\mathrm{C} 3$ in the dataset. Figure S5 shows the optimal thresholds for BWE verification across the dataset and their associated success rates. 
Table S1. Experimental design and sampling frequency on nine research cruises. BWE treatments include unexchanged control (C), exchanged by Empty-Refill method (ER) or exchanged by Flow Through method (FT).

\begin{tabular}{|c|c|c|c|c|}
\hline Cruise Identifier & SF & LA & PS & Fos \\
\hline Vessel Name & SR Benicia & MV Overseas Boston & MV Tonsina & MV Mosel Ore \\
\hline Departure port & San Francisco (CA) & LA Longbeach (CA) & Cherry Point (WA) & Fos Sur Mer (FR.) \\
\hline $\begin{array}{l}\text { Original source of } \\
\text { ballast water in tanks }\end{array}$ & $\begin{array}{c}\text { Mixture San Francisco } \\
(70 \%), \text { Puget sound } \\
(30 \%)\end{array}$ & Longbeach & Puget Sound & Mediterranean Sea \\
\hline Date & Nov. 5-13, 2000 & Dec. 9-12, 2000 & May 18-21, 2001 & Jun. 13-25, 2001 \\
\hline Cruise length (days) & 7 & 7 & 4 & 14 \\
\hline Vessel Type, Cargo & Oil Tanker ,Oil & Oil Tanker ,Oil & Oil Tanker ,Oil & Bulk Carrier ,Coal \\
\hline BWE locations $(N)$ & NE. Pacific (4) & NE. Pacific (2) & $\begin{array}{l}\text { a. NE. Pacific (3) } \\
\text { b. NE. Pacific (2) }\end{array}$ & $\begin{array}{l}\text { Mid-E. Atlantic (3) } \\
\text { Mid-W. Atlantic (3) }\end{array}$ \\
\hline Treatments & $\mathrm{C}, \mathrm{ER}, \mathrm{FT}$ & $\mathrm{C}, \mathrm{FT}$ & $\mathrm{C}, \mathrm{ER}$ & $\mathrm{C}, \mathrm{ER}, \mathrm{FT}$ \\
\hline No. ballast tanks & 1 per treatment & 1 per treatment & 1 per treatment & 4 per treatment \\
\hline Type ballast tanks & Wing & Wing & Wing & Wing \\
\hline No. times sampled & 3-4 per tank & 3 per tank & 2 per tank & 4 or 5 per tank \\
\hline Sampling depth & $1,12 \mathrm{~m}$ & $<1,11 \mathrm{~m}$ & $<1,12 \mathrm{~m}$ & $1,4 \mathrm{~m}$ \\
\hline $\begin{array}{l}\text { No. samples: } \\
\text { Unexch./Exch./Ocean }\end{array}$ & $19 / 10 /-$ & $16 / 1 /-$ & $24 / 8 /-$ & $79 / 32 / 13$ \\
\hline Additional samples $(N)$ & partial BWE (4) & partial BWE (4) & near-shore (16) & $\begin{array}{l}\text { partial BWE (32), } \\
\text { cruise track (37) }\end{array}$ \\
\hline Cruise Identifier & LF & AS & $\begin{array}{ll}\text { a. } \mathrm{K} 1 & \text { b. } \mathrm{K} 2\end{array}$ & BN \\
\hline Vessel Name & MV Lily Fortune & MV Asahi Sunrise & MV Kauai & MV Berge Nord \\
\hline Departure port & Haramachi (JAP.) & Yokkaichi (JAP.) & $\begin{array}{l}\text { a. Oakland, CA } \\
\text { b. Honolulu, HI }\end{array}$ & Rotterdam (NL.) \\
\hline $\begin{array}{l}\text { Original source of } \\
\text { ballast water in tanks }\end{array}$ & Haramachi (JAP.) & $\begin{array}{l}\text { Yokkaichi (JAP.) and } \\
\text { Kunsan or Inchon, } \\
\text { (KOR.), }\end{array}$ & $\begin{array}{l}\text { a. Oakland, CA } \\
\text { b. Honolulu, } \mathrm{HI}\end{array}$ & Rotterdam (NL.) \\
\hline Date & Jun. 5-16, 2003 & Aug. 5-17, 2003 & Jun. 19 - Jul. 6, 2004 & Sep. 10-23, 2004 \\
\hline Cruise length (days) & 12 & 13 & $\begin{array}{l}\text { a. } 3 \\
\text { b. } 4\end{array}$ & 14 \\
\hline Vessel Type, Cargo & Bulk Carrier, Coal & Bulk Carrier, Soda ash & Container Ship, Mixed & Bulk Carrier, Iron ore \\
\hline BWE locations (N) & N. Pacific (4) & N. Pacific (4) & $\begin{array}{l}\text { a. NE. Pacific (3) } \\
\text { b. NE. Pacific (2) }\end{array}$ & $\begin{array}{l}\text { N. Atlantic (3) } \\
\text { Mid-Atlantic (3) } \\
\text { S. Atlantic (3) }\end{array}$ \\
\hline Treatments & $C, E R$ & $\mathrm{C}, \mathrm{FT}$ & $C, E R$ & $\mathrm{C}, \mathrm{FT}$ \\
\hline No. ballast tanks & 4 per treatment & 5 per treatment & 3 per experiment & 3 per treatment \\
\hline Type ballast tanks & Wing & Wing & Double bottom & Wing \\
\hline No. times sampled & 2-6 per tank & 2-7 per tank & 2 per tank/experiment & 4 per tank \\
\hline Sampling depth & 1,2 or $3 \mathrm{~m}$ & 1,2 or $3 \mathrm{~m}$ & $<1 \mathrm{~m}$ & $1,12 \mathrm{~m}$ \\
\hline $\begin{array}{l}\text { No. samples } \\
\text { Unexch./Exch./Ocean }\end{array}$ & $58 / 50 / 7$ & $62 / 38 / 8$ & $\begin{array}{l}\text { a. } 14 / 10 / \text { - } \\
\text { b. } 12 / 20 / \text { - }\end{array}$ & $39 / 35 / 25$ \\
\hline Additional samples $(\mathrm{N})$ & cruise track (26) & cruise track (26) & - & cruise track (31) \\
\hline
\end{tabular}




\section{Page S2. Spectral comparisons from fluorometers used in this study.}

Systematic differences between instruments increase variation within the dataset and can reduce the likelihood that spectral signatures will be accurately represented. The analytical laboratories that analyzed CDOM EEMs for this study (University of South Florida using a SPEX FluoroLog-2; University of Maine using a SPEX FluoroMax-2; National Environmental Research Institute, Denmark, using a Varian Cary Eclipse) participated in an intercalibration experiment during a two week period in October 2004. Using Quinine Sulfate Standard Reference Material (SRM 936) (50 ppb) and their standard EEMs analysis and correction protocols, each laboratory produced fully corrected EEMs at $20^{\circ} \mathrm{C}$. When normalized to peak height, the emission scans at $\lambda_{\mathrm{ex}}=350 \mathrm{~nm}$ corresponded closely to the relative technical emission spectrum for Quinine Sulfate dehydrate of Velapoldi and Mielenz (1980) (1) (Figure $\mathrm{S} 1)$, referred to hereafter as the technical emission spectrum.

The FluoroLog-2 and FluoroMax-2 were operated at their highest sensitivity settings (factory specified signal/noise ratios $>4000 / 1$ and $>20000 / 1$ respectively) and produced smooth peaks. The Varian was operated at a relatively low sensitivity setting (detection limits for humic fluorescence $<0.25 \mathrm{ppb}$ QSE (2)), greatly decreasing analysis time but resulting in noticeable scatter. For all three instruments, deviations from the technical emission spectrum were less than $\pm 10 \%$ of peak height (data lying within horizontal grey lines) across most of the wavelength range.

At emission wavelengths $380-430 \mathrm{~nm}$, all three instrument curves displayed similar slight shoulders due to incomplete correction for interference scatter at Raman wavelengths $\left(\lambda_{\text {ex }}=398\right.$ $428 \mathrm{~nm}$ at $\lambda_{\mathrm{ex}}=350 \mathrm{~nm}$ ). Data from the FluoroMax-2, which was the only instrument with a single monochrometer on the emission side, had additional peaks at wavelengths corresponding 
to secondary Rayleigh and Raman scatter (i.e. $\lambda_{\mathrm{ex}} \sim 500,545 \pm 15 \mathrm{~nm}$ at $\lambda_{\mathrm{ex}}=250 \mathrm{~nm}$ ). Low resolution of $\mathrm{CDOM}$ fluorescence in scatter regions is to be expected and did not affect the results of this study.
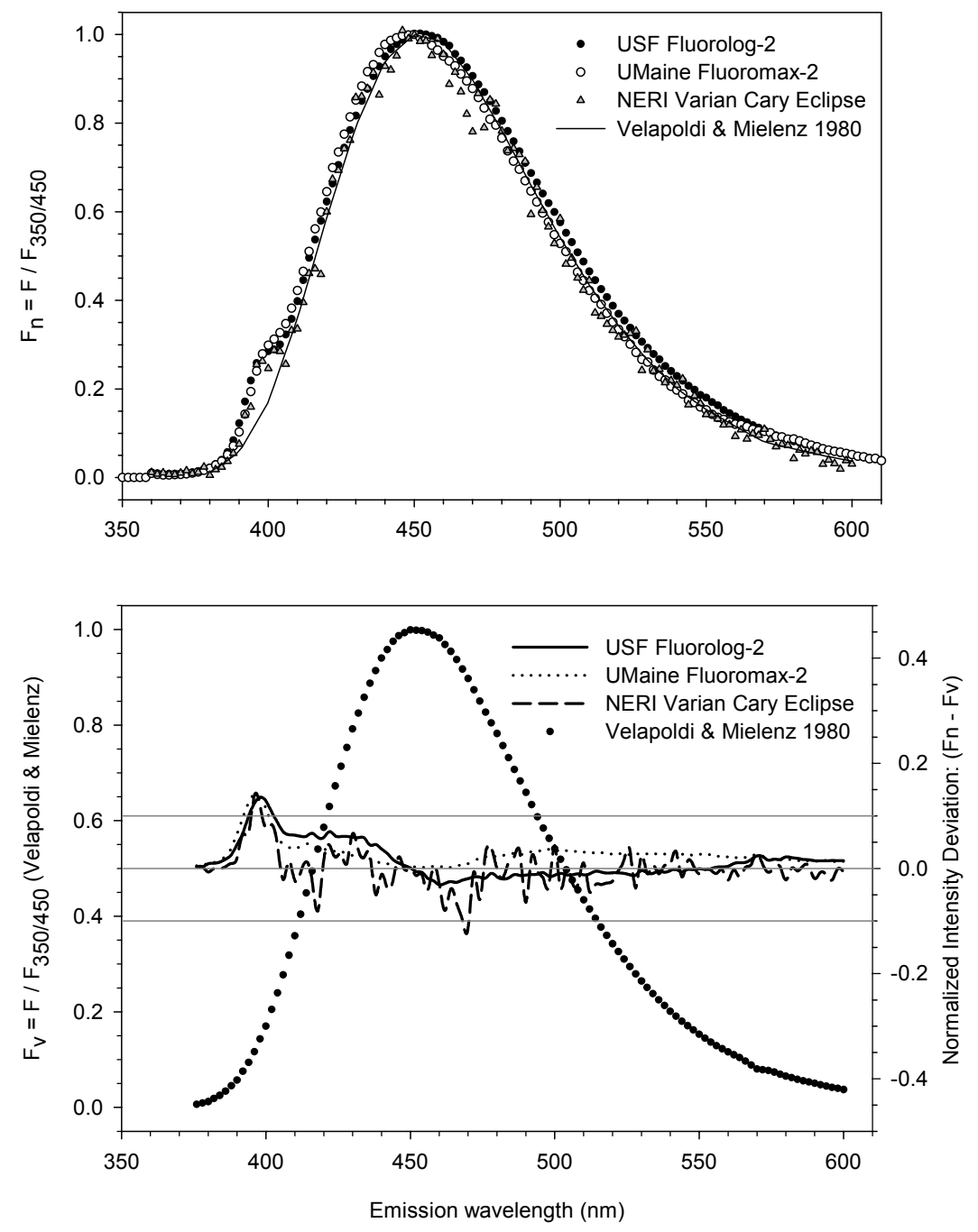

Figure S1: Normalized emission scans from fluorometers in this study, compared with the relative technical emission spectrum of Velapoldi \& Mielenz (1980) (19). A) Emission scan at at $\lambda_{\text {ex }}=350 \mathrm{~nm}$ of Quinine Sulfate dehydrate standard (50 ppb); B) Deviations relative to the Velapoldi curve at $\lambda_{\text {ex }}=350 \mathrm{~nm}$. For wavelengths unaffected by Raman scatter, deviations are less than $\pm 10 \%$ of peak height (data lying within horizontal grey lines). 
Table S2. Primary and secondary excitation $\left(\lambda_{\mathrm{ex}}\right)$ and emission $\left(\lambda_{\mathrm{em}}\right)$ maxima for nine fluorescent components identified by the PARAFAC model.

\begin{tabular}{|lll|}
\hline Component & $1^{\circ}\left(2^{\circ}\right) \lambda_{\text {ex }}(\mathrm{nm})$ & $\lambda_{\text {em }}(\mathrm{nm})$ \\
\hline C1 & 275 & $<300$ \\
C2 & 315 & 418 \\
C3 & $260(370)$ & 490 \\
C4 & $250(320)$ & 370 \\
C5 & $255(280)$ & 580 \\
C6 & 280 & 328 \\
C7 & $<240(300)$ & 338 \\
C8 & $250(380)$ & 416 \\
C9 & $<240$ & 422 \\
\hline
\end{tabular}



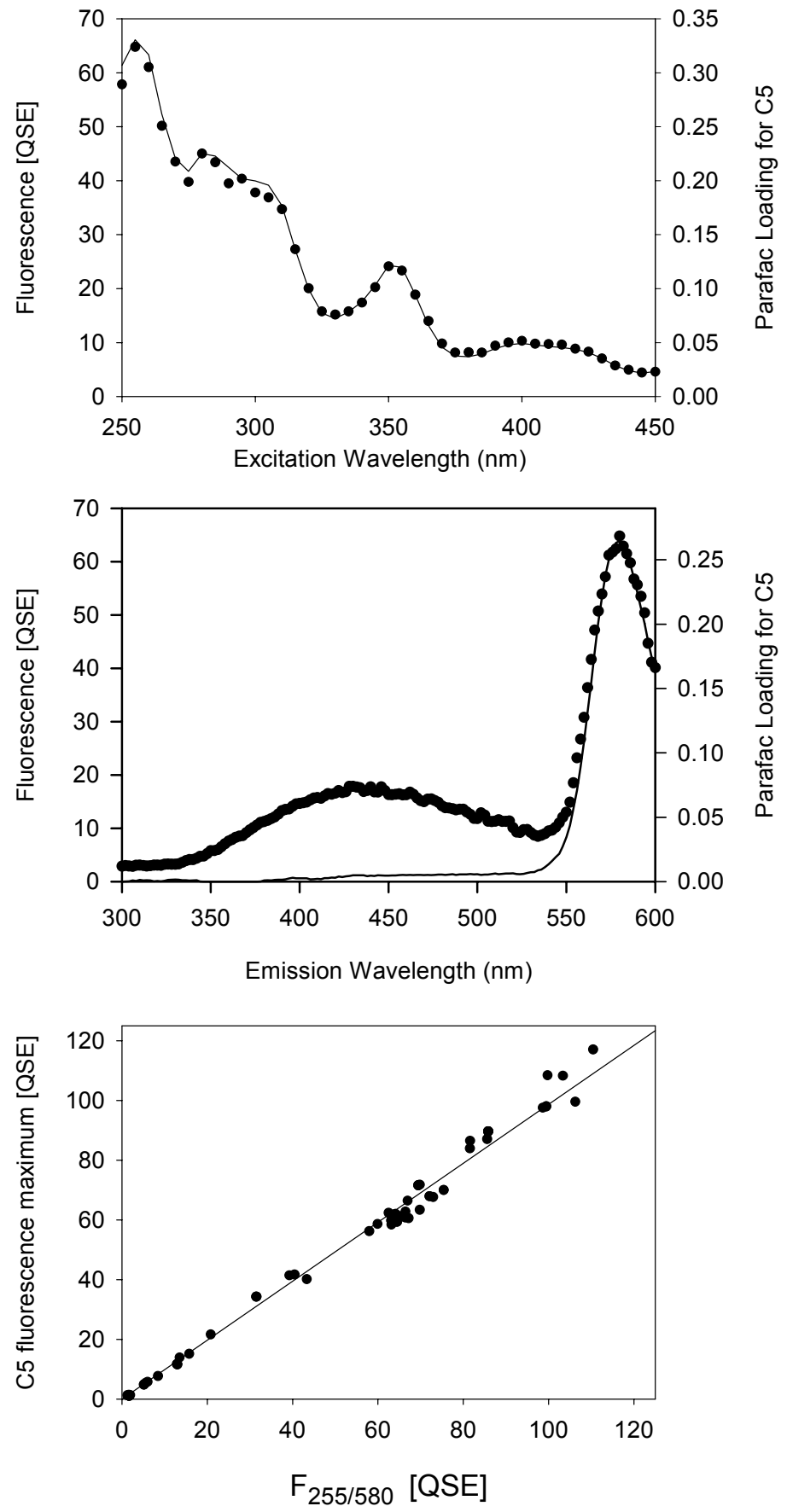

Figure S2. Validation of PARAFAC model using Rhodamine dye. (A) Excitation scan $\left(\lambda_{\mathrm{em}}=580\right.$ $\mathrm{nm})$ from sample 50001 on Cruise SF $(\bullet)$ corresponds closely with excitation spectrum for PARAFAC component C5 (line). (B) Emission scan $\left(\lambda_{\text {ex }}=255 \mathrm{~nm}\right)$ from same sample (•) with overlaid PARAFAC emission spectrum (line) shows minimal overlap with CDOM for $\lambda_{\mathrm{em}}<530$ $\mathrm{nm}$. (C) Linear regression of fluorescence at maximum intensity $\left(\mathrm{F}_{255 / 580}\right)$ in all samples containing dye vs. PARAFAC component $\mathrm{C} 5_{\max }$ shows excellent recovery of fluorescence intensity by the model $\left(C 5_{\max }=0.987 * F_{255 / 580}, R^{2}=0.99, N=73\right)$. 

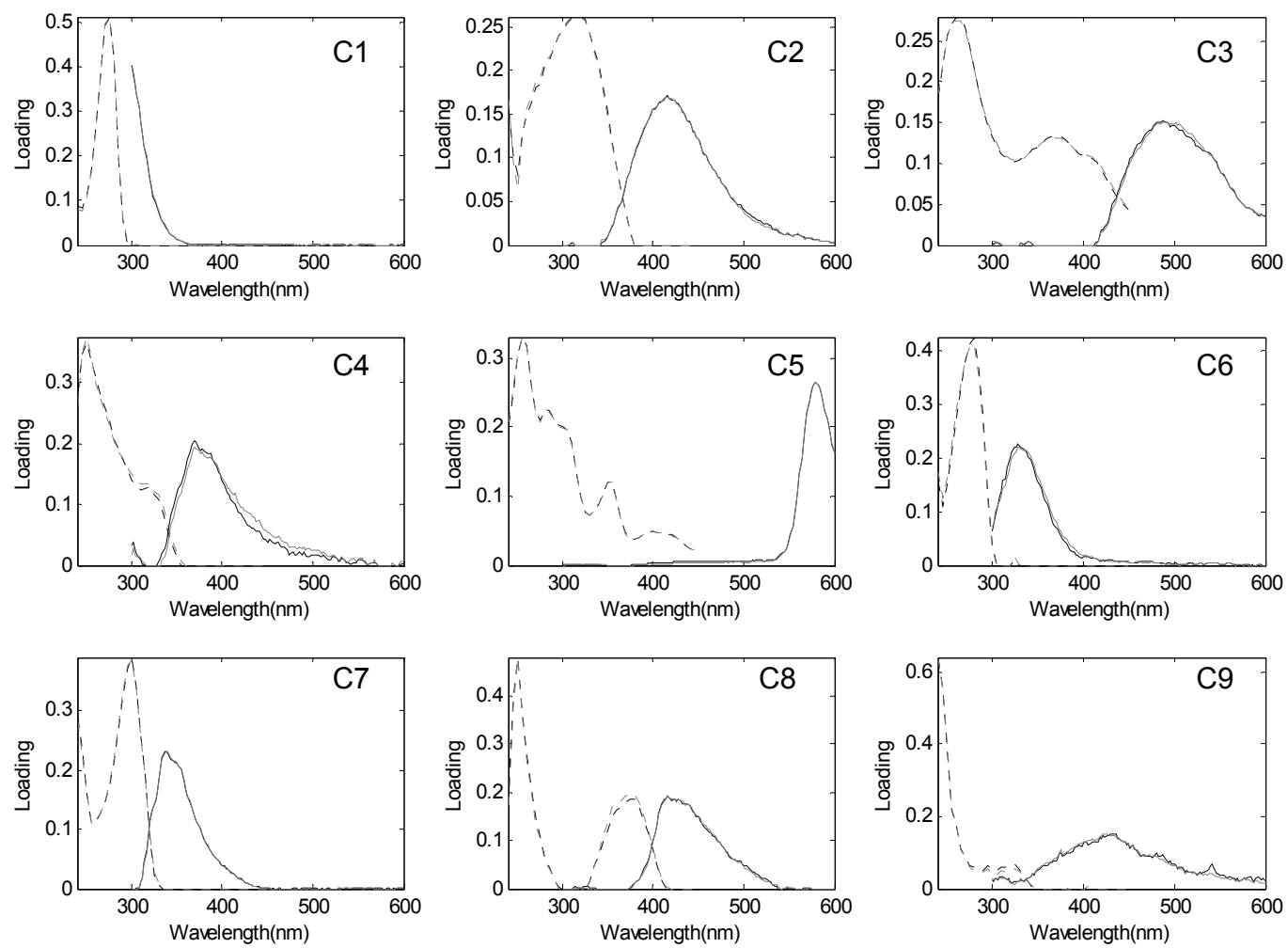

Figure S3. Validation of PARAFAC model by split-half analysis. Excitation spectra (dashed lines) and emission spectra (solid lines) of nine independent PARAFAC components (C1-C9) in two random halves of the calibration dataset (black and grey lines). 
S6. Procedure for determining optimal wavelengths and thresholds for component isolation and BWE verification.

'Optimal' excitation and emission wavelengths for measuring components $\mathrm{C} 2$ and $\mathrm{C} 3$ were determined on the basis of two factors: degree of isolation and rate of successful BWE verification. Isolation of a component at each wavelength pair was determined by calculating a component's contribution, $F_{i}$, to total fluorescence, $F_{t}$, using the ratio $F_{i} / F_{t}$, averaged across all samples in the calibration dataset (Figure S4).
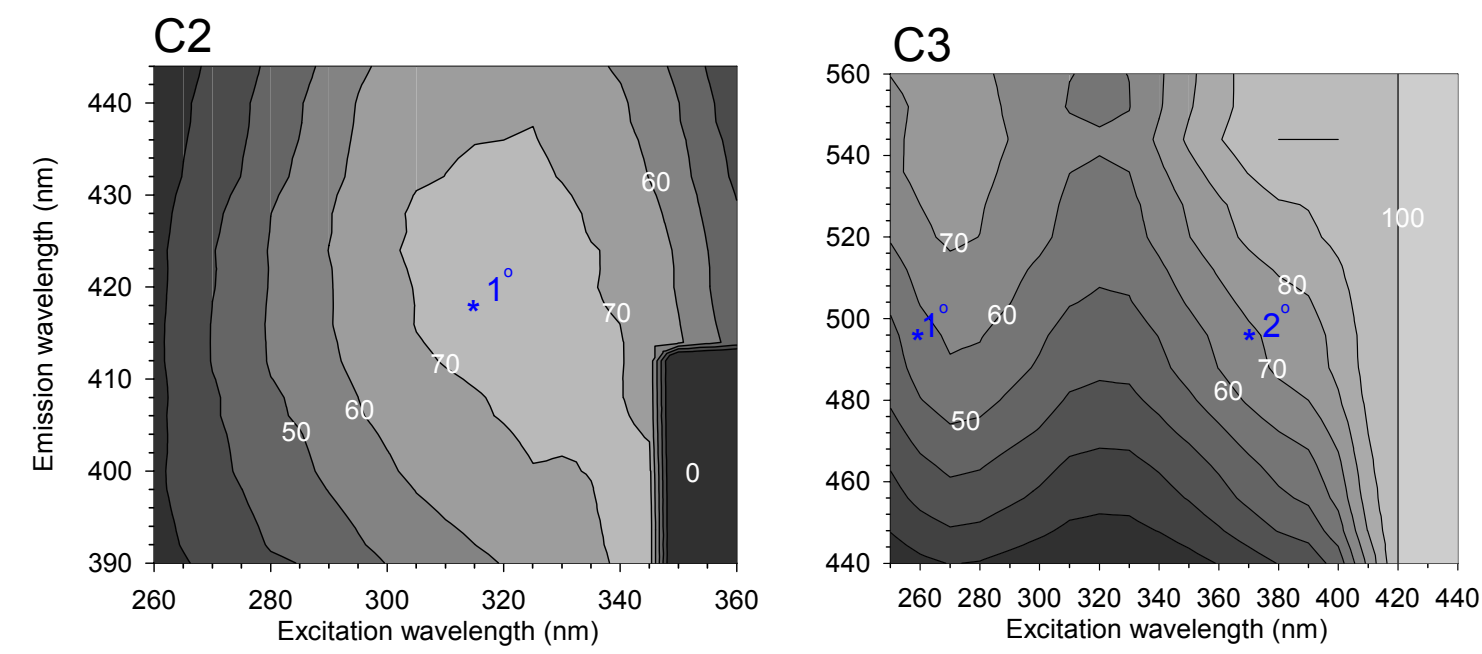

Figure S4: Average isolation $\left(F_{i} / F_{t}\right)$ of components $\mathrm{C} 2$ and $\mathrm{C} 3$ in ballast water samples from the calibration dataset $(N=443)$. Positions of primary $\left(1^{\circ}\right)$ and secondary $\left(2^{\circ}\right)$ excitation and emission maxima are indicated.

To assess suitability for verifying BWE, an optimal intensity threshold, to the nearest $0.1 \mathrm{ppb}$, was defined for each wavelength pair as the highest fluorescence intensity that divided exchanged from unexchanged ballast water samples in a manner that minimized the total number of misidentifications. Optimal thresholds for BWE mimic the shape of an EEM (Figure S5A). 
Rates of misidentified samples using optimal thresholds were lowest in the region of component $\mathrm{C} 3$, and highest at short excitation and emission wavelengths (components $\mathrm{C} 1, \mathrm{C} 6$ and $\mathrm{C} 7$ ) and in the diagonal band influenced by water Raman scatter (Figure S5-B).
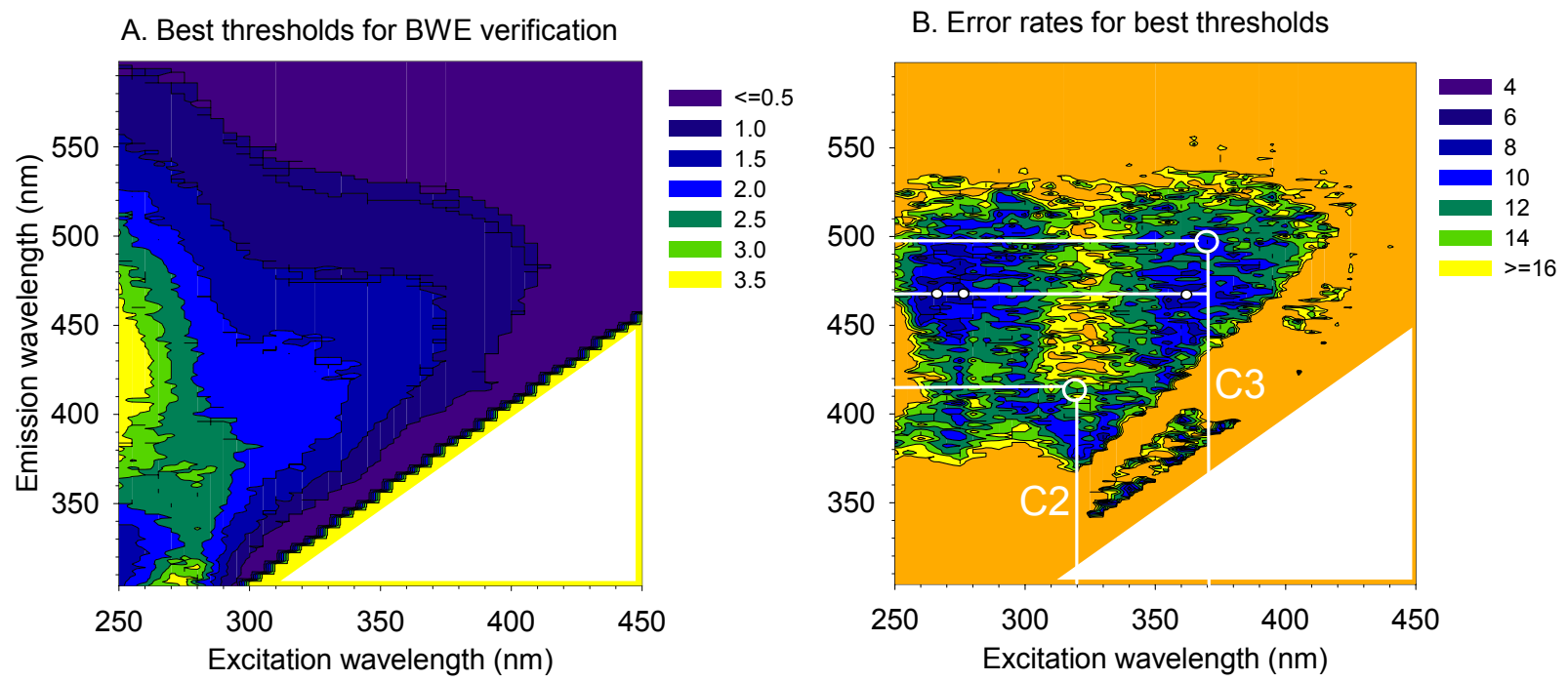

Figure S5: Best fluorescence thresholds for BWE verification and their associated misidentification rates. A) Fluorescence intensity thresholds for BWE (ppb QSE) that minimize misidentification rates across the calibration dataset; B) 'Optimal' wavelength pairs for measuring components $\mathrm{C} 2$ and $\mathrm{C} 3$ are indicated by hollow circles, while three positions $\left(\lambda_{\text {em }}=466, \lambda_{\text {ex }}=\right.$ 265,275 and $360 \mathrm{~nm}$ ) with potential for targeting multiple components are indicated by white circles.

For component $\mathrm{C} 3$, low misidentification rates were achieved in the regions of both the primary $\left(\lambda_{\mathrm{ex}} / \lambda_{\mathrm{em}}=260 / 490\right)$ and secondary $\left(\lambda_{\mathrm{ex}} / \lambda_{\mathrm{em}}=370 / 490\right)$ peaks. Isolation was higher at the secondary than primary peak (67\% versus 54\%); at the primary peak, overlap was approx. 10 $15 \%$ from each $\mathrm{C} 2, \mathrm{C} 4, \mathrm{C} 8$ and $\mathrm{C} 9$ while at the secondary peak, overlap was mainly from $\mathrm{C} 8$ $(\sim 20 \%)$ and $\mathrm{C} 2(\sim 10 \%)$. Although similar rates of misidentification were attainable near the primary peak, positions near the secondary peak may be more suitable for measuring C3 due to greater isolation and conformity with excitation filters in many existing handheld fluorometers (see S1). Rates of successful BWE verification were maximized near the secondary peak at C3* 
$=370 / 496 \mathrm{~nm}$ (Threshold $=0.7$ QSE, 8 misidentifications). Misidentifications near C3* $( \pm 5 \mathrm{~nm}$ excitation, $\pm 6 \mathrm{~nm}$ emission) numbered 13 or less from a total of 459 samples (i.e. misidentification rate $<3 \%$ ).

Misidentifications were more frequent for component $\mathrm{C} 2$. Overlap near the fluorescence maximum $\left(\lambda_{\mathrm{ex}} / \lambda_{\mathrm{em}}=315 / 418,72 \%\right.$ isolated $)$ was due mainly to $\mathrm{C} 4(\sim 16 \%)$, with minor contributions from $\mathrm{C} 7(\sim 4 \%)$ and $\mathrm{C} 9(\sim 6 \%)$. Rates of successful BWE verification were maximized at $\mathrm{C} 2 *: \lambda_{\mathrm{ex}} / \lambda_{\mathrm{em}}=320 / 414 \mathrm{~nm}$ (Threshold $=1.7$ QSE, 12 misidentifications). Misidentifications in the neighborhood of $\mathrm{C} 2 *( \pm 5 \mathrm{~nm}$ excitation, $\pm 6 \mathrm{~nm}$ emission) numbered 16 or less (i.e. misidentification rate $<3.5 \%$ ).

High verification success rates for the calibration dataset were also achieved in regions with significant overlaps from multiple components (see also Table 2 of the paper). For example, rates at $\lambda_{\text {em }}=466( \pm 6 \mathrm{~nm}), \lambda_{\text {ex }}=265,275$ and $360( \pm 5 \mathrm{~nm})$ were all similar at $<2 \%$, despite contributions by components $\mathrm{C} 2, \mathrm{C} 3, \mathrm{C} 4, \mathrm{C} 8$ and $\mathrm{C} 9$ ranging between $5-45 \%$. This reflected the situation that in all ballast water samples, concentrations of different humic-like components were highly correlated.

\section{References}

(1) Velapoldi, R. A.; Mielenz, K. D. "Standard reference materials: A fluorescence standard reference material- quinine sulfate dihydrate," National Bureau of Standards, 1980.

(2) Stedmon, C. A.; Markager, S. Tracing the production and degradation of autochthonous fractions of dissolved organic matter using fluorescence analysis. Limnol. Oceanogr. 2005, 50, 1415-1426. 